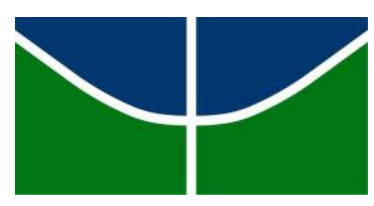

Universidade de Brasília

Instituto de Ciências Biológicas

Programa de Pós- Graduação em Ecologia

\title{
Variação sazonal na composição química de detritos foliares em zonas ripárias do Cerrado
}

\author{
Laís de Souza Lima
}

Orientador: Prof. Dr. José Francisco Gonçalves Junior

$$
\text { Brasília - DF }
$$

Outubro de 2015 


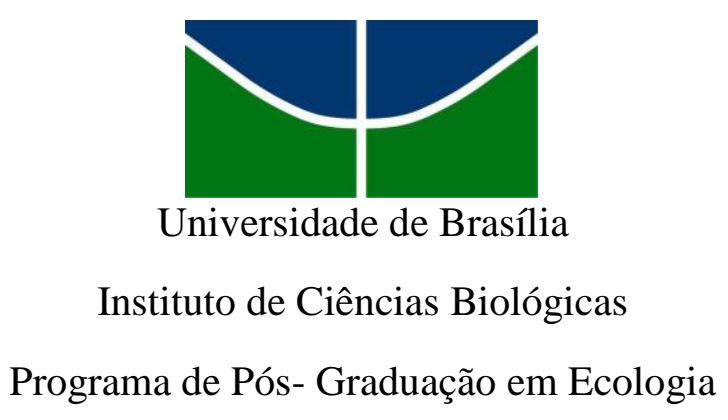

\title{
Variação sazonal na composição química de detritos foliares em zonas ripárias do Cerrado
}

\author{
Laís de Souza Lima \\ Orientador: Prof. Dr. José Francisco Gonçalves Junior \\ Dissertação de mestrado apresentada ao \\ Departamento de Ecologia da Universidade de \\ Brasília pelo Programa de Pós-Graduação em \\ Ecologia como requisito para obtenção do título \\ de Mestre em Ecologia
}

Brasília - DF

Outubro de 2015 


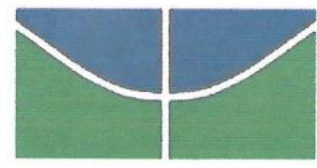

UNIVERSIDADE DE BRASILIA INSTITUTO DE CIÊNCIAS BIOLÓGICAS DEPARTAMENTO DE ECOLOGIA PROGRAMA DE PÓS GRADUAÇÄO EM ECOLOGIA

Dissertação de Mestrado

LAIS DE SOUZA LIMA

Título:

\section{"Variação sazonal na composição química de detritos foliares em zonas ripárias do Cerrado"}

Banca examinadora:

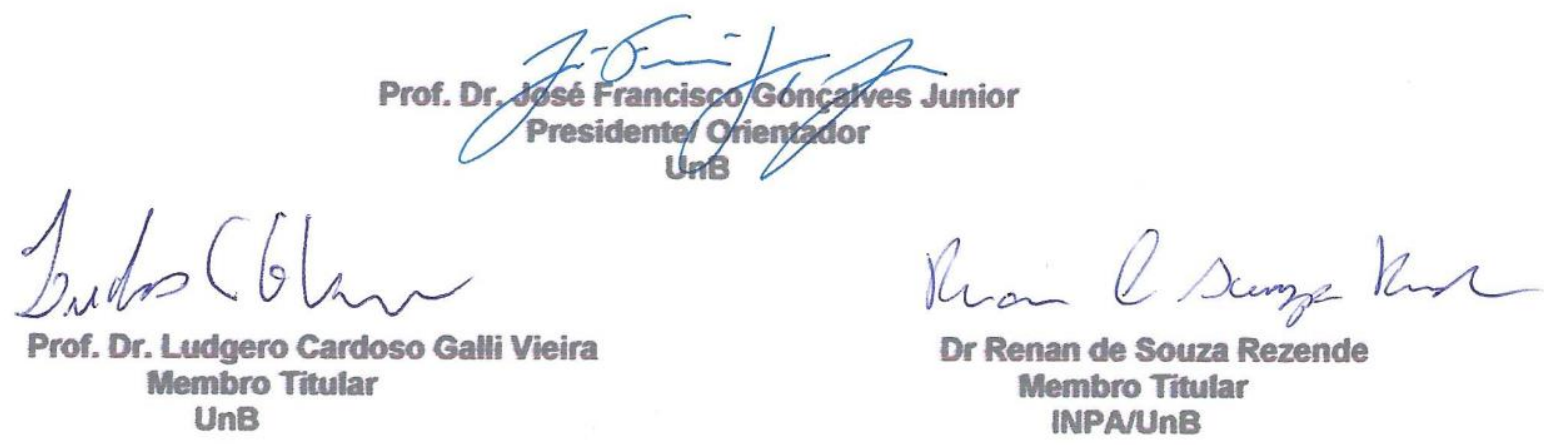

Dr. Rafael Dudeque Zenni Membro Suplente

UnB 
"Estar vivo e ter uma consciência não é apenas um privilégio, mas também uma grande responsabilidade."

Carl Sagan. 


\section{AGRADECIMENTOS}

Ao meu amado marido, Vitto César, pelo amor, apoio, carinho, compreensão e paciência durante todo o tempo que estamos juntos. Pelas horas suadas e dedicadas para a produção das figuras. Meu amor, esse trabalho também é seu.

Aos meus pais e irmãos que sempre torceram pelo meu sucesso. Pelas marmitas, faxinas, cuidado e muito amor que tenho recebido esse tempo todo.

Ao meu querido orientador prof. Dr. José Francisco Gonçalves Junior, pela confiança, compreensão, dedicação e por ser tão flexível com a forma de se trabalhar. Por ser apaixonado pelo que faz, você é uma inspiração.

Aos meus queridos amigos Alan e Suéle que também dedicaram várias horas para me explicar com toda paciência como fazer ciência em ecologia. Pelas análises estatísticas e pela amizade sincera.

Às minhas amigas de infância Jaqueline, Fernanda, Caroline e Cínthia pelas horas de distração, pelo apoio, pelos pitacos, risadas e por sempre torcerem pelo meu sucesso. Vocês são minha segunda família.

Aos amigos do laboratório de limnologia: Patrícia, Alessandra, Paulino, Renan, Gustavo, Monique e Luísa pela ajuda com as análises, com a vidraria, com os reagentes, com as discussões que contribuíram muito para este trabalho e com a nossa boa convivência no laboratório. Gosto muito dessa equipe!

À Capes pela bolsa e à UnB pela infra-estrutura e apoio financeiro na participação de eventos e congressos nacionais.

Muito obrigada. 


\section{SUMÁRIO}

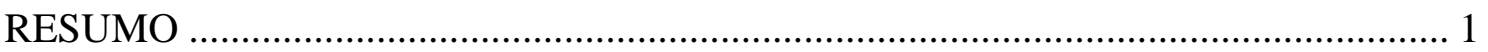

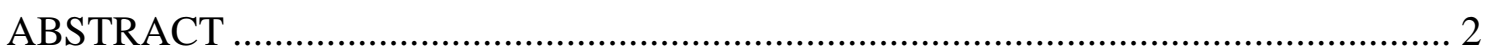

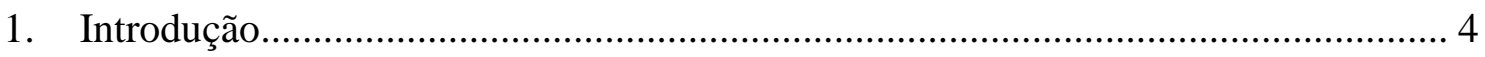

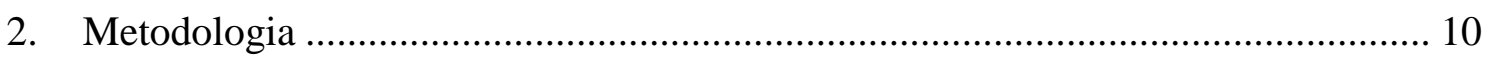

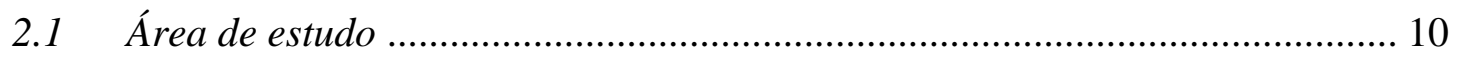

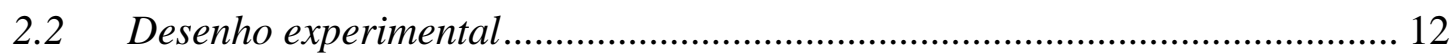

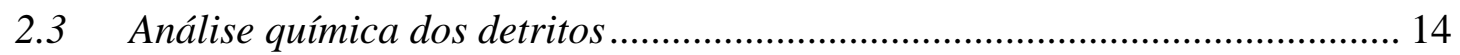

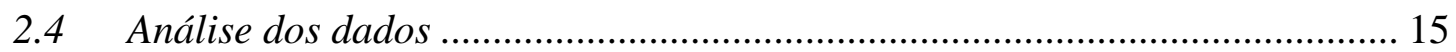

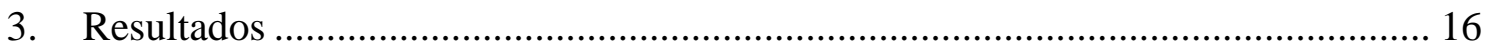

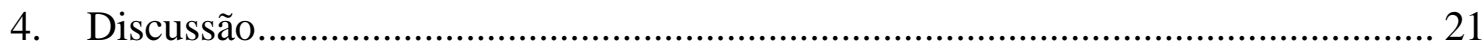

Padrão sazonal da Química dos detritos foliares ................................................... 21

Efeito da composição química do detrito foliar nos processos ecológicos ................. 24

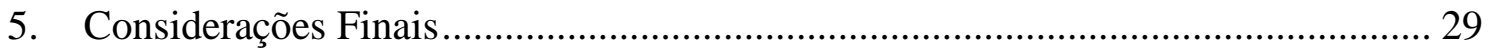

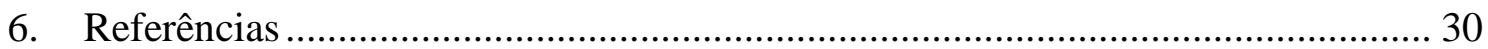




\section{RESUMO}

A matéria orgânica da vegetação ripária adjacente aos riachos de pequena ordem é a principal fonte de energia para o ecossistema aquático, sendo o detrito foliar o que tem maior contribuição biológica para os riachos, em termos de biomassa e nutrientes. Assim, a composição química do detrito foliar é um fator regulador da qualidade do detrito para os micro-organismos, vertebrados e invertebrados aquáticos, uma vez que a cadeia trófica desses ecossistemas é baseada em detritos. Além de influenciar a cadeia trófica, a qualidade do detrito também influencia outros processos ecológicos, como a decomposição e a ciclagem biogeoquímica, em riachos de cabeceira. O objetivo deste estudo foi avaliar as variações temporais na composição química dos detritos foliares que entram nos riachos do Cerrado, a partir da seguinte hipótese: os detritos foliares tem menor concentração de nitrogênio e fósforo na estação seca devido à reabsorção destes elementos pelas plantas no período de maior perda de folhas. Da mesma forma, esperase que a razão $\mathrm{C}$ : $\mathrm{N}$ e C: $\mathrm{P}$ seja maior na época seca. $\mathrm{O}$ experimento foi realizado em três riachos de pequena ordem preservados em Brasília, DF. As coletas foram realizadas mensalmente durante 24 meses (entre setembro de 2010 e agosto de 2012). As espécies dos 11 primeiros meses foram identificadas, contudo os detritos dos 24 meses foram moídos misturados. Foram feitas análises químicas para quantificação de nutrientes ( $\mathrm{N} \mathrm{e}$ P), de polifenóis, fibras, lignina e celulose. A composição química dos detritos foliares foi comparada com a precipitação. Os resultados mostram que a composição química dos detritos está fortemente relacionada com o clima do Cerrado. Os detritos foliares são mais ricos em compostos secundários e estruturais na estação seca do que na estação chuvosa. Adicionalmente, a quantidade de nutrientes é menor na estação seca e a razão C:P e C:N é maior, corroborando nossa hipótese. Portanto a qualidade do detrito que cai na época 
seca é pior para os organismos detritívoros do que a que cai na estação chuvosa. Comparando os dados de nutrientes deste estudo com a cronologia da biota aquática da literatura, conclui-se que existe um padrão temporal da dinâmica nutricional, da colonização dos detritos por micro-organimos e da atividade de invertebrados detritívoros em relação à estacionalidade climática do Cerrado. Este padrão reflete nos processos ecológicos, como a decomposição, a ciclagem biogeoquímica e a disponibilidade de nutrientes no ecossistema ripário do Cerrado.

Palavras-chave: riacho, qualidade do detrito, nutrientes, polifenóis, lignina, celulose.

\section{ABSTRACT}

The organic matter from riparian vegetation that bounds streams are the primary energy source to the aquatic ecosystem. Allochthonous leaf litter have a pronounced biological contribution to streams. The chemical composition of leaf litter plays an important role in leaf litter quality to the aquatic microorganisms, to the litter breakdown process and to the nutrient cycling, since the food webs from these systems are detritus based. The aim of this study was to assess temporal variation on leaf litter chemical composition from the Cerrado riparian vegetation. We hypothesized that leaf litter has lower concentration of nitrogen and phosphorus during the dry season because of nutrient resorption before leaf abscission. Therefore, the $\mathrm{C}: \mathrm{N}$ and $\mathrm{C}: \mathrm{P}$ ratios would be higher during the dry season. The study was carried out in three low order preserved streams in Brasília, Brazil. Samples were collected monthly during 24 months (between September of 2010 and august 2012). The 11 firsts months species were identified, however, all the 24 collected months were ground mixed. We measured nutrient ( $\mathrm{N}$ and $\mathrm{P})$, polyphenol, fiber, lignin and celluloses content. Thereafter we compared the leaf litter chemical composition with precipitation. 
The results shows that leaf litter chemical composition is narrowly related to the Cerrado climate. Leaf litter are more concentrated on secondary and structural compounds during the dry season than the rainy season. Nevertheless, nutrient content is lower during the dry season, and $\mathrm{C}: \mathrm{N}$ and $\mathrm{C}: \mathrm{P}$ ratios are higher, which confirms our hypothesis. Therefore, the leaf litter that falls on the dry season is of worse quality to the aquatic detritivores than the litterfall from the rainy season. Putting together our nutrient results with studies from literature about streams biota, we conclude that there is a relation between temporal pattern of nutritional dynamics, leaf colonization, the detritivorous invertebrates and seasonal climate from Cerrado. This pattern results on ecological processes such as decomposition rate, biogeochemical cycle and nutrient availability the Cerrado riparian ecosystem.

Key- words: stream, leaf litter quality, nutrients, polyphenols, lignin, cellulose.

(As referências bibliográficas seguiram o padrão da revista Freshwater Biology) 


\section{Introdução}

Os rios de pequena ordem representam cerca de $50 \%$ de uma bacia hidrográfica em termos de extensão e apresentam inúmeras funções ecológicas, entre elas: transporte de matéria orgânica, regulação hidrológica, regulação de temperatura, além de atuarem como corredores de dispersão de fauna e plantas (Naiman et al, 2005; Berkowitz et al., 2014). Esses rios são relativamente estreitos e a copa das árvores da vegetação ripária fecha o dossel acima do sistema lótico, diminuindo a entrada de luz e, consequentemente, a produtividade primária do ecossistema aquático (Vannote et al., 1980). Dessa forma, a principal fonte de energia advém da vegetação ripária na forma de material orgânico alóctone (Wallace et al., 1997). Esse material orgânico serve como alimento, sítio reprodutivo e refúgio para diversas espécies aquáticas, e pode ainda afetar indiretamente a biota aquática ao criar barreiras físicas e retenção de outras substâncias (e.g. sedimento, carcaças e excretas de animais) provenientes do ambiente terrestre (Teresa \& Casatti, 2010).

A relação íntima entre os ecossistemas terrestre e aquático faz do ecossistema ripário um sistema ecológico complexo e fundamental para os rios (Gregory et al., 1991), para a vitalidade da paisagem e para a bacia hidrográfica (Naiman et al., 2000). Nesse ecótono dinâmico entre o sistema aquático e o terrestre, ocorre uma série de processos ecológicos como: a prevenção de erosão das margens, retenção e filtragem de substâncias nocivas (e.g. agrotóxicos), transferência de energia, nutrientes, sedimentos e organismos (Wantzen et al., 2008). A dinâmica energética pode ocorrer por vetores meteorológicos, geológicos e biológicos, fazendo da interface terrestre-aquática um ecossistema ripário com características intrínsecas (Seifert \& Scheu, 2012).

As zonas ripárias do bioma Cerrado apresentam acentuada estacionalidade climática (Lima \& Silva, 2008), apesar das florestas tropicais serem conhecidas como 
florestas perenes (Wantzen et al., 2008). A estação seca vai de junho a outubro e a chuvosa de novembro a maio com precipitação média de até $2.000 \mathrm{~mm}$ por ano (Lima \& Silva, 2008). No período seco, o fluxo de água nos riachos é menor e a entrada de folhas é maior, portanto há um maior incremento de biomassa foliar no final dessa época do ano (Gonçalves et al., 2014). Na estação chuvosa, a precipitação aumenta o fluxo da água e a matéria orgânica é carreada à jusante, diminuindo o acúmulo de matéria orgânica nos riachos (Acuña et al., 2007). O bioma Cerrado desempenha importante papel na distribuição hídrica do país, onde estão localizadas nascentes das bacias hidrográficas mais importantes da América do Sul: Bacia do São Francisco, Tocantins-Araguaia e Paraná-Paraguai (Lima \& Silva, 2008). As zonas ripárias do bioma Cerrado estão localizadas em fundos de vales, com inclinações suaves ou acentuadas que contêm elevada variação de microhabitats (Ribeiro \& Walter, 2001). Algumas espécies arbóreas de zonas ripárias do Cerrado podem ser encontradas em outros biomas tropicais onde se formam ecótonos (transição Mata Atlântica-Cerrado e Amazônia-Cerrado), o que torna essas zonas importantes fontes de dispersão de fauna e flora (França et al., 2009).

O aporte de matéria orgânica para os riachos proveniente da vegetação ripária ocorre diretamente (aporte vertical) ou indiretamente (aporte lateral). $\mathrm{O}$ aporte direto pode refletir a influência de padrões fenológicos (Abelho, 2001), de variáveis climáticas (i.e. chuva e vento; Zhang et al., 2014) e da diversidade de espécies ao longo do trecho do rio (Gonçalves \& Callisto, 2013). O aporte indireto pode ser influenciado pela inclinação do terreno, largura do rio, movimento da fauna e também por variáveis climáticas (Naiman et al., 2005). Uma vez dentro dos riachos, a matéria orgânica pode ser retida e formar o estoque bêntico, ou ser transportada à jusante pelo fluxo da água (Abelho, 2001). Ao ficar retida no córrego, a matéria orgânica torna-se disponível para a comunidade microbiana, para invertebrados detritívoros e para vertebrados (Speaker et al., 1984). Essa matéria 
orgânica pode ser classificada de acordo com o tamanho de suas partículas: (i) grossa (> $1 \mathrm{~mm})$, formada por galhos, folhas, frutos, flores; (ii) fina $(<1 \mathrm{~mm}>0,05 \mathrm{~mm})$, resultante da degradação de partículas grossas por organismos consumidores; e (iii) dissolvida (> 0,05 mm) formada por compostos químicos dissolvidos, excretas de algas e animais, percolação e lixiviação terrestre (Esteves \& Gonçalves, 2011). As partículas de matéria orgânica grossa desempenham papel ecológico relevante na disponibilidade de energia para a biota aquática uma vez que a cadeia trófica destes sistemas é detritívora (Larrañaga et al., 2003). Os detritos foliares são os maiores contribuintes da matéria orgânica particulada grossa, colaborando com 41 a $98 \%$ da matéria orgânica da vegetação alóctone (Lisboa et al., 2015).

A maior parte da produção das plantas terrestres é consumida como detrito (Ricklefs, 2010), especialmente em riachos de pequena ordem onde as copas das árvores sombreiam o leito do rio impedindo a produção autóctone pelas algas (Naiman et al., 2005). Sabe-se que as espécies lenhosas das matas de galeria tem altas taxas de uso eficiente dos nutrientes (Parron, 2004) e que o "turnover" de nutrientes em florestas maduras é muito mais lento, os quais ficam acumulados na biomassa viva (Boeger et al., 2005). Em florestas maduras a taxa de crescimento dos tecidos vegetais é lenta e a demanda por nutrientes também é menor (Dosskey et al., 2010), por isso a porcentagem de nutrientes das folhas senescentes é muito menor do que nas folhas verdes. A menor disponibilidade de nutrientes no ambiente devido à retenção dos mesmos na biomassa viva, faz das zonas ripárias um filtro para saída de nutrientes do meio terrestre para o meio aquático e, assim, contribuem para a manutenção da qualidade da água do córrego.

A decomposição dos detritos foliares é um processo chave para a liberação de carbono e para o ciclo de nutrientes tanto em ambientes terrestres quanto aquáticos, e depende de fatores ambientais como temperatura, $\mathrm{pH}$, turbidez, salinidade, carbono e 
oxigênio dissolvido na água (Abelho, 2001; Pettit et al., 2012). No entanto, a decomposição de detritos foliares é influenciada principalmente pelos constituintes químicos presentes nos detritos, os quais definem a qualidade química do material (Hoorens et al., 2002; Guendehou, 2014). Cada espécie possui necessidades nutricionais distintas de absorção, reabsorção, estoque e perda de nutrientes (Gonzáles, 2012), desta forma, cada espécie tem concentrações de nutrientes diferentes e diferem na velocidade de decomposição (Kominoski et al., 2007). No entanto, alguns estudos demonstram que a taxa de decomposição da mistura de espécies difere da decomposição de cada espécie separadamente (Leroy \& Mark, 2006; Moretti et al., 2007; Lecerf et al., 2007). Portanto, espécies ricas em nutrientes podem acelerar o processo de decomposição de espécies mais recalcitrantes ou vice-versa (Hoorens et al., 2002). A diversidade biológica e ambiental de florestas tropicais, como a diversidade de solos e temperaturas, torna esse sistema muito mais complexo que os ambientes temperados (Townsend et al., 2007). Assim, é importante entender o funcionamento de florestas tropicais levando em consideração a qualidade da mistura de detritos de espécies que compõem o bioma tropical.

A qualidade dos detritos foliares para os organismos decompositores é determinada pelos nutrientes (nitrogênio e fósforo) e pela qualidade do carbono orgânico. Enquanto carboidratos simples são facilmente decompostos (açúcares simples), cadeias complexas de carbono presentes em compostos estruturais são difíceis de serem degradadas (e.g. lignina e celulose; Ardón et al., 2006). Além dos compostos estruturais, os compostos secundários, como os polifenóis, são produzidos a fim de evitar herbivoria e patógenos. Em ambientes terrestres, a presença de polifenóis pode inibir o crescimento de hifas e a produção de esporos fúngicos (Hättenschwiler \& Vitousek, 2000). Além disso, a capacidade de precipitar proteínas faz com que os polifenóis se liguem à compostos orgânicos de $\mathrm{N}$, dificultando a decomposição dessa matéria orgânica (Meier 
\& Bowman, 2008; Kraus et al. 2004). Portanto, além de evitar a herbivoria e influenciar o processo de decomposição, os polifenóis também desempenham funções na ciclagem de nutrientes devido à capacidade de se adsorverem a partículas de argila, Fe e Al e reduzirem a toxicidade desses elementos em solos ácidos, como é o caso do Cerrado, intervindo na quantidade e disponibilidade de nutrientes do ambiente (Hättenschwiler \& Vitousek, 2000; Meier \& Bowman, 2008). Pressupõe-se que essas funções são verdadeiras também para ambientes aquáticos, contudo, não há estudos referentes à esse assunto para riachos. A matéria orgânica das zonas ripárias do Cerrado, geralmente, é de baixa qualidade para os detritívoros. Isso porque a vegetação local tem altas taxas conservativas dos nutrientes $\mathrm{N}$ e $\mathrm{P}$, em que a concentração desses elementos na biomassa é muito maior do que a disponibilidade deles no ambiente (Parron et al. 2011). Da mesma forma, a presença de compostos estruturais e secundários - como fibras, lignina, celulose e os polifenóis- podem ser uma adaptação das plantas a ambientes oligotróficos, como é o caso das florestas tropicais (Kraus et al., 2003).

Geralmente, estudos que avaliaram a qualidade dos detritos foliares utilizaram espécies particulares ou uma combinação de menos de cinco espécies (Hoorens et al., 2003; Moretti et al. 2007; Lovett et al., 2002) para testar a influência desta sobre taxas de decomposição (Guendehou et al., 2014), colonização microbiana ou preferência alimentar de invertebrados detritívoros (Graça, 2001). No entanto, um número muito reduzido de estudos explorou as variações naturais na qualidade química dos detritos que entram nos riachos (Sales et al., 2014), mesmo considerando que a qualidade desse material é determinante para sua decomposição (Lecerf et al., 2007). Além disso, variações naturais na qualidade química podem ser ainda mais importantes em ambientes diversos como as zonas ripárias do Cerrado, onde mais de 20 espécies contribuem para o aporte de matéria orgânica (Gonçalves \& Callisto, 2013). 
A composição de espécies e o regime hidrológico são os principais fatores que explicam a quantidade, a qualidade e a fenologia do detrito (Boyero et al., 2009; Abelho, 2001). A sazonalidade afeta a dinâmica do detrito e, consequentemente, o suprimento de matéria orgânica e a disponibilidade de luz para a vida aquática (Acuña et al., 2007). Alguns estudos revelaram uma dinâmica temporal da matéria orgânica ao longo de um ano, em que nem todas as espécies vegetais eram encontradas todos os meses no aporte vertical (Sales et al., 2014; França et al., 2009; Gonçalves \& Callisto, 2013). Portanto, espécies diferentes perdem suas folhas em épocas distintas, ou seja, existe elevada diversidade fenológica entre as espécies ripárias (Silva, 2014). As variações temporais na composição química do detrito podem ter uma importância pronunciada uma vez que a sazonalidade tem fortes efeitos sobre o funcionamento de ecossistemas ripários (Gonzáles, 2012). Por exemplo: o ciclo de vida de invertebrados detritívoros é sincrônico com a fenologia das espécies, e a ocorrência desses insetos é convergente com a qualidade do detrito foliar (Wantzen e Wagner, 2006). Além disso, a dinâmica temporal da qualidade do detrito é um importante regulador dos ciclos biogeoquímicos (Parsons et al., 2014). Portanto, entender como a qualidade do detrito foliar varia em função do tempo pode auxiliar a compreender a fenologia das plantas ripárias, os efeitos ecossistêmicos e pode ser uma ferramenta para fazer predições sobre como ela varia em resposta às mudanças ambientais e climáticas (Schiller et al., 2008; Parsons et al., 2014).

O estudo de Sales et al. (2014) foi um dos primeiros a avaliar como ocorrem as variações químicas de misturas naturais (i.e. manteve as proporções das espécies que entram naturalmente nos riachos) de detritos foliares em riachos tropicais. Para eles a qualidade química dos detritos incubados não variou ao longo de um ano de estudo. No entanto, foram avaliadas folhas já incubadas nos riachos, o que pode ter homogeneizado as amostras (efeito aditivo). Além disso, os autores não avaliaram a quantidade de 
nitrogênio nos detritos, o qual é um dos nutrientes mais importantes para os organismos. Por outro lado, Parsons et al. (2014) observaram uma variação intra-anual na composição química dos detritos foliares, em que havia maior concentração de compostos recalcitrantes na estação seca do que na estação chuvosa, o que tem implicações para a decomposição e para os ciclos biogeoquímicos.

Diante do exposto, o objetivo deste trabalho foi avaliar as variações sazonais na composição química dos detritos foliares que entram nos riachos do Cerrado. Nestes ecossistemas tropicais, a queda das folhas ocorre durante todo o ano, porém é mais acentuada na estação seca, uma vez que as plantas liberam as folhas em resposta ao estresse hídrico (Gonçalves \& Callisto, 2013). Baseado na premissa de que as plantas tropicais tem uma função conservativa dos nutrientes (Parron et al., 2011), nossa hipótese é que os detritos foliares tem menor concentração de nitrogênio e fósforo na estação seca, devido à reabsorção destes elementos pelas plantas no período de maior perda de folhas. Isto levaria a maior razão $\mathrm{C}$ : $\mathrm{N}$ e $\mathrm{C}$ : $\mathrm{P}$, uma vez que a concentração de $\mathrm{C}$ seria menos variável ao longo do tempo. Além disso, a menor disponibilidade de água no solo durante a estação seca, ocasiona um investimento maior na produção de compostos recalcitrantes (Kraus et al. 2003, 2014). Portanto espera-se encontrar maior concentração desses compostos nos detritos na estação seca.

\section{Metodologia}

\section{1 Área de estudo}

As formações vegetais que beiram as nascentes são denominadas vegetação ripária. No Cerrado, elas podem ser dos subtipos: mata inundável ou mata não-inundável, dependendo da topografia e da variação anual do aquífero. Na mata inundável, o lençol freático se mantém próximo ou sobre a superfície do terreno com topografia plana durante 
todo o ano, mesmo na estação seca. Na mata não-inundável, a topografia é acidentada, a linha de drenagem é bem definida e o lençol freático não se mantém próximo da superfície. A composição florística de cada subtipo de mata tem diferentes características, no entanto existem espécies que ocorrem indistintamente nas duas matas (Ribeiro \& Walter, 2008).

A fisionomia da vegetação na mata é perenifólia e quase sempre é circundada por faixas de vegetação não florestal havendo uma transição evidente com formações savânicas e com os campos (Ribeiro \& Walter, 2001). A alta densidade de plantas arbóreas com 20 a 30 metros de altura, resulta em estrato herbáceo-arbustivo pouco desenvolvido, mas a alta disponibilidade de água mantém a umidade mesmo durante a estação seca e permite o estabelecimento de lianas e epífitas (Silva Junior et al., 2001).

O presente trabalho foi realizado em três riachos de pequena ordem, representantes da bacia hidrográfica Paraná, localizados na Área de Preservação Ambiental (APA) Gama-Cabeça-de-Veado. A APA compreende as unidades de conservação: Fazenda Água Limpa, da Universidade de Brasília; Reserva Ecológica do IBGE e Jardim Botânico de Brasília (Felfili e Felfili, 2001). Foram escolhidos três riachos similares preservados: um de $3^{a}$ ordem e não-inundável na Fazenda Água Limpa, um de $2^{\mathrm{a}}$ ordem e inundável na Reserva Ecológica do IBGE, outro de $2^{\mathrm{a}}$ ordem e não-inundável no Jardim Botânico de Brasília (Figura 1).

Foram levantados dados da composição florística responsável pelo aporte vertical, ou seja, pelos detritos que caíam diretamente no riacho, durante o primeiro ano de estudo, ou seja, durante onze meses (setembro de 2010 a julho de 2011). No Jardim Botânico as espécies que mais contribuíram para o aporte vertical foram Sacoglottis guianensis, Cybianthus gardneri, Protium spruceanum e Ormosia arborea, respectivamente. Na FAL as espécies mais representativas foram Salacia elliptica, Vochysia piramidalis, Protium 
spruceanum, e Emmotum nitens, respectivamente. No IBGE as espécies que mais contribuíram foram Rapanea parvifolia, Lamanonia ternata, Myrcia laruotteana e Rapanea guianensis, respectivamente (Paulino Bambi, dados não publicados).

\subsection{Desenho experimental}

As coletas foram realizadas mensalmente durante dois anos, com início em setembro de 2010 e término em agosto de 2012. Em cada riacho foram selecionados cinco pontos amostrais, que distavam 10 metros entre si, totalizando um trecho de aproximadamente 50 metros de curso d'água. Em cada ponto, foram colocadas três fileiras de baldes, distantes aproximadamente um metro entre si, totalizando 15 fileiras por riacho (Figura 2).

O aporte vertical da matéria orgânica foi coletado por meio de três fileiras de baldes suspensos por cordas a aproximadamente dois metros de altura, amarradas em cada margem do riacho, perpendiculares ao curso d'água. Estas fileiras foram compostas por seis baldes com 25 centímetros de diâmetro, com furos no fundo dos baldes para evitar o acúmulo de água. 


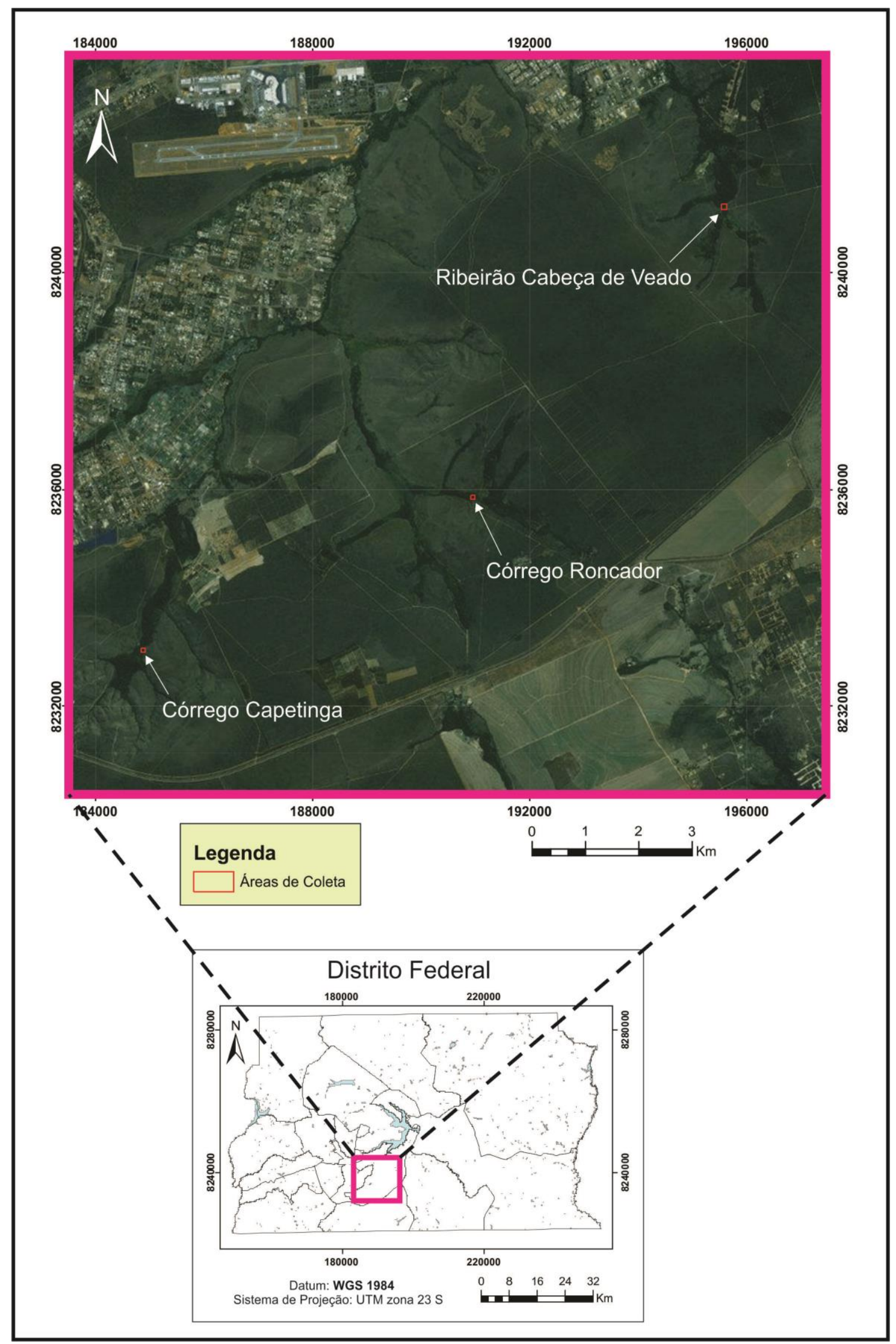

Figura 1 - Localização geográfica dos riachos da APA Gama-Cabeça-de-Veado. O ribeirão Cabeça de Veado está inserido do Jardim Botânico de Brasília; o córrego 
Roncador no IBGE; e o córrego Capetinga na Fazenda Água Limpa da Universidade de Brasília.

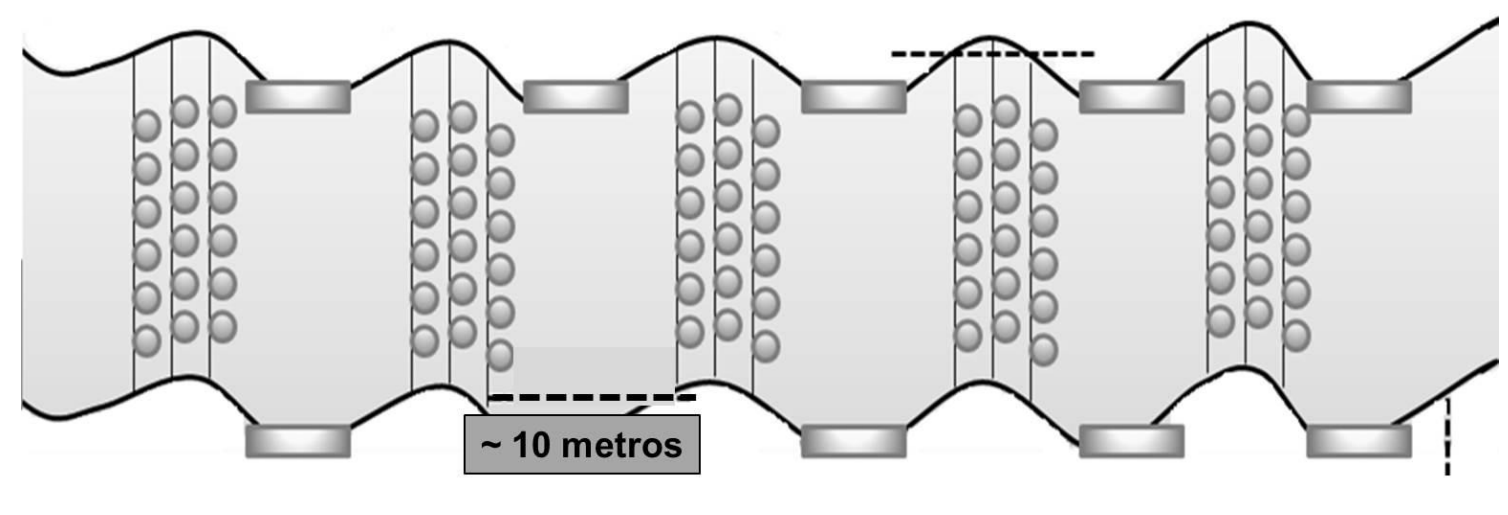

$\sim 50$ metros

Figura 2 - Desenho esquemático da disposição dos baldes ao longo do riacho (linha contínua). Em cada ponto havia três fileiras compostas por seis baldes, totalizando 18 baldes por ponto.

\subsection{Análise química dos detritos}

A matéria orgânica coletada dos baldes foi seca em estufa a $60 \mathrm{C}^{\circ}$ por 72 horas, em seguida foi triada (folhas, partes reprodutivas, galhos, outros), pesada em balança de precisão de 0,1 mg e identificada. Posteriormente, juntou-se os detritos foliares das três fileiras de baldes em cada ponto, formando uma amostra composta. $\mathrm{O}$ detrito foliar de cada ponto foi moído em malha de $0.5 \mathrm{~mm}$ para posterior análise de composição química desse detrito. Portanto, a unidade amostral foi o detrito foliar de cada ponto, em cada mês e em cada riacho. Os demais componentes da matéria orgânica coletada (flores, frutos, galhos e outros) não foram utilizados nesse trabalho.

Para obtenção de polifenóis totais foi utilizado o método de Folin-Ciocalteau (1927) através da estimativa de concentração de grupos fenólicos hidroxila. Foram pesados 100 mg dos detritos moídos e os polifenóis foram extraídos em acetona 70\% por 
1 hora na geladeira. Em seguida, centrifugou-se a amostra e uma alíquota de 0,3 ml do sobrenadante foi retirada para leitura em espectofotômetro $(760 \mathrm{~nm})$. O cálculo da concentração de fenóis foi baseado numa curva de calibração com concentração conhecida (Barlocher \& Graça, 2005).

As concentrações de fibras, lignina e celulose, foram determinadas por gravimetria a partir de $250 \mathrm{mg}$ de detritos moídos. A proporção de cada composto foi estimada através do peso residual das amostras depois das sucessivas remoções de cada tecido com ácido-detergente, ácido sulfúrico $72 \%$ e queima em mufla a $550{ }^{\circ} \mathrm{C}$ (Gessner, 2005).

Para análise de fósforo total, digeriu-se $5 \mathrm{mg}$ das cinzas dos detritos em ácido clorídrico. A quantificação de fósforo total nos detritos foi estimada por digestão ácida com ácido clorídrico (Barlocher \& Graça, 2005). Para quantificação de carbono e nitrogênio foi utilizado o método de combustão total a $950^{\circ} \mathrm{C}$ de amostras secas em um analisador elementar (modelo Truspec CHN628, Leco Instruments Ltda, St Joseph, Michigan, USA 2013), o qual detecta carbono e nitrogênio sob a forma de $\mathrm{CO}_{2}$ e $\mathrm{N}_{2}$, respectivamente, por meio de células de infravermelho e de condutividade térmica.

\subsection{Análise dos dados}

A normalidade dos dados foi avaliada a partir do teste Kolmogorov-Smirnov para verificar se as variáveis seguem uma distribuição normal (Gaussiana). A homocedasticidade - para testar a homogeneidade das variâncias - foi feita a partir do teste Levene e os valores $\ln (+1)$ foram transformados, quando necessário. A proporção (\%) de nitrogênio, fósforo, carbono, polifenol, fibras, lignina e celulose (variáveis resposta) no detrito foliar do aporte vertical ao longo dos dois anos (variável explanatória) 
foi analisada por uma ANOVA de medidas repetidas (RM-ANOVA) utilizando os locais e as amostras como medidas repetidas (Crawley, 2007).

Para testar a relação da composição química do detrito foliar com a precipitação mensal de cada ano, foi feita análise de regressão linear considerando o tempo como variável contínua e os riachos como réplicas.

\section{Resultados}

Os detritos foliares apresentarem baixas concentrações dos nutrientes nitrogênio, com média menor que $2 \%$ de nitrogênio no detrito, e fósforo, com média menor que $1 \%$ no detrito (Tabela 1). A figura 3 ilustra a variação temporal de cada constituinte químico ao longo dos 24 meses estudados. Apesar da baixa quantidade de nutrientes, a variação sazonal desses elementos foi significativa, em que o nitrogênio $\left(F_{1 ; 59}=20,34 ; P<0,001\right)$ e o fósforo $\left(\mathrm{F}_{1 ; 59}=10,95 ; \mathrm{P}<0,001\right)$ foram encontrados em maior quantidade na estação chuvosa, ou seja, entre novembro e maio. A razão estequiométrica entre C:N ( $\mathrm{F}_{1 ; 59}=$ $26,15 ; \mathrm{P}<0,001)$ e $\mathrm{C}: \mathrm{P}\left(\mathrm{F}_{1 ; 59}=12,22 ; \mathrm{P}<0,001\right)$ dos detritos foi significativamente maior na estação seca do que na estação chuvosa (Figura 4).

Tabela 1- Valores médios, desvio padrão, mínimos e máximos da concentração (\% peso seco) dos compostos químicos dos detritos foliares do aporte direto em cada estação: seca e chuvosa. 


\begin{tabular}{l|ccc|ccc}
\hline $\begin{array}{l}\text { Composição } \\
\text { Química }\end{array}$ & \multicolumn{3}{|c|}{ Seca } & \multicolumn{3}{|c}{ Chuva } \\
& média \pm DP & Mínimo & Máximo & média \pm DP & Mínimo & Máximo \\
\hline & & & & & & \\
$\mathrm{N}$ & $1,115 \pm 0,151$ & 0,858 & 1,408 & $1,299 \pm 0,188$ & 0,929 & 2,1 \\
$\mathrm{P}$ & $0,011 \pm 0,002$ & 0,007 & 0,02 & $0,014 \pm 0,003$ & 0,007 & 0,023 \\
Polifenóis & $4,874 \pm 1,661$ & 2,068 & 8,678 & $2,637 \pm 0,776$ & 1,376 & 4,496 \\
Fibras & $67,291 \pm 20,238$ & 52,934 & 171,204 & $71,502 \pm 3,928$ & 62,583 & 79,867 \\
Lignina & $22,048 \pm 2,431$ & 17,293 & 27,119 & $23,013 \pm 2,192$ & 17,6 & 26,521 \\
Celulose & $39,07 \pm 5,917$ & 31,167 & 59,22 & $45,213 \pm 4,452$ & 34,65 & 54,25 \\
C:N & $45,023 \pm 5,681$ & 35,033 & 55,934 & $39,093 \pm 4,979$ & 23,033 & 53,093 \\
C:P & $4425,7 \pm 1011,2$ & 2509,05 & 6498,04 & $3701,2 \pm 803,1$ & 2225,93 & 6541,68 \\
\hline
\end{tabular}

A concentração de polifenóis foi significativamente maior na estação seca $\left(\mathrm{F}_{1 ; 59}=\right.$ 51,64; P < 0,001; Tabela 1; Figura 4) com picos nos meses de agosto e setembro. Dentre os compostos estruturais analisados: fibras, lignina e celulose, apenas a concentração de celulose variou entre as estações seca e chuvosa, atingindo valores maiores na estação chuvosa $\left(\mathrm{F}_{1 ; 59}=27,55 ; \mathrm{P}<0,001\right.$; Tabela 1; Figura 4). Esse resultado também foi evidenciado na relação entre precipitação e os constituintes do detrito foliar, em que a celulose foi positivamente relacionada com a pluviosidade (Figura 5).

As variáveis analisadas foram significativamente relacionadas com a precipitação (Figura 5), apenas a lignina não teve relação com esse fenômeno. A concentração dos nutrientes $\mathrm{N}$ e $\mathrm{P}$ foi positivamente relacionada com a precipitação, ou seja, quanto maior a disponibilidade de água, maior é a quantidade desses nutrientes no detrito foliar. A razão estequiométrica $\mathrm{C}: \mathrm{N}$ e $\mathrm{C}: \mathrm{P}$ é negativamente relacionada com a disponibilidade de água, isso quer dizer que a quantidade de carbono no detrito é maior do que a quantidade de nutrientes durante a época seca.

Dentre as 140 espécies lenhosas identificadas, 20 espécies são encontradas em elevadas proporções ao longo de 11 meses e três (Protium spruceanum, Xylopia emarginata e Calophyllum brasiliense) são encontradas quase durante todos os meses. 
Contudo, a entrada dessas espécies no riacho não ocorre de maneira uniforme durante o ano todo, variando temporalmente entre os meses.

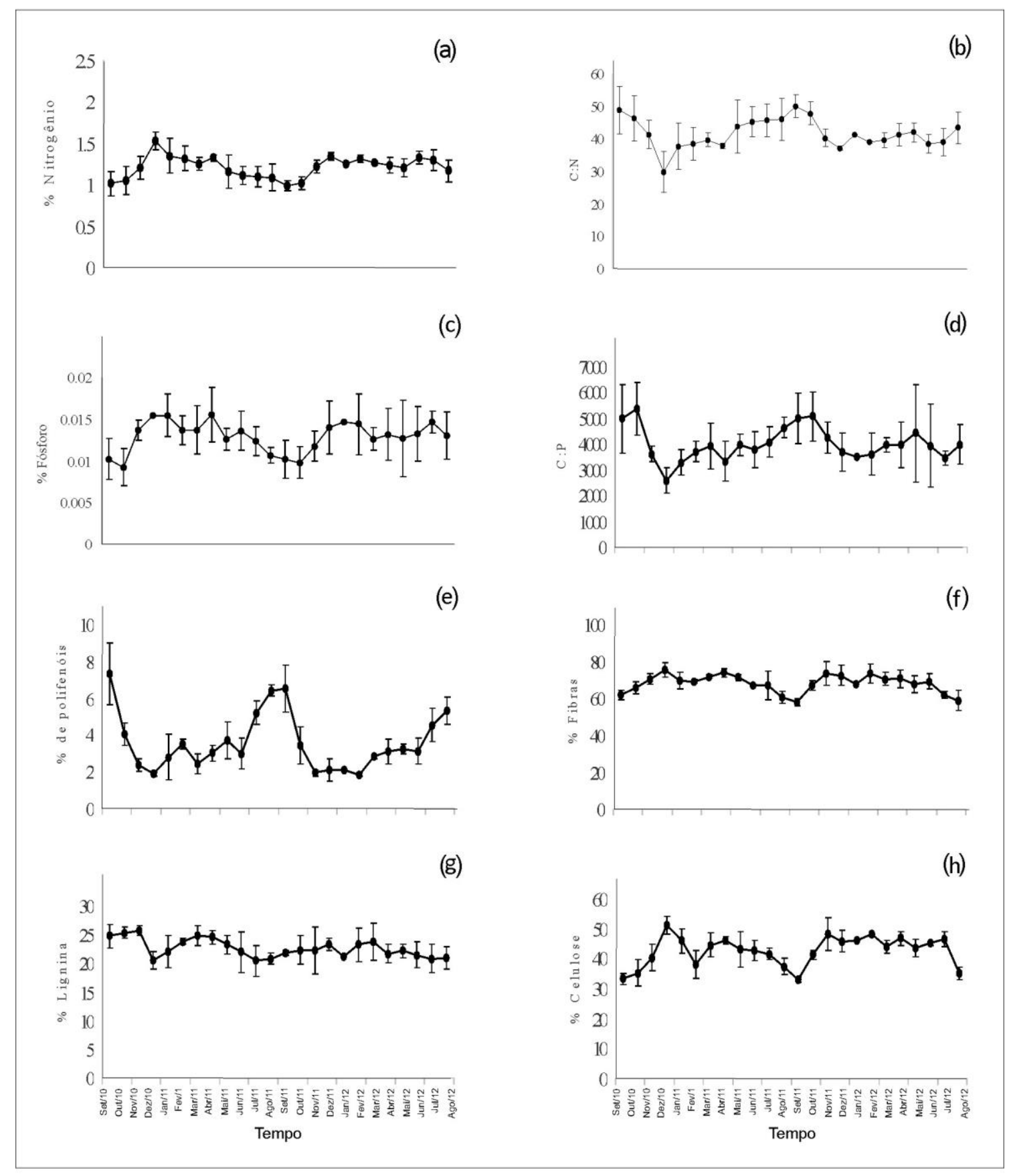

Figura 3 - Variação temporal dos compostos químicos no detrito foliar do aporte direto ao longo de 2 anos nos riachos estudados: (a) N; (b) razão estequiométrica C:N; (c) P; 
(d) razão estequiométrica C:P; compostos secundários (e) polifenóis; e estruturais: (f) fibras; (g) lignina e (h) celulose.
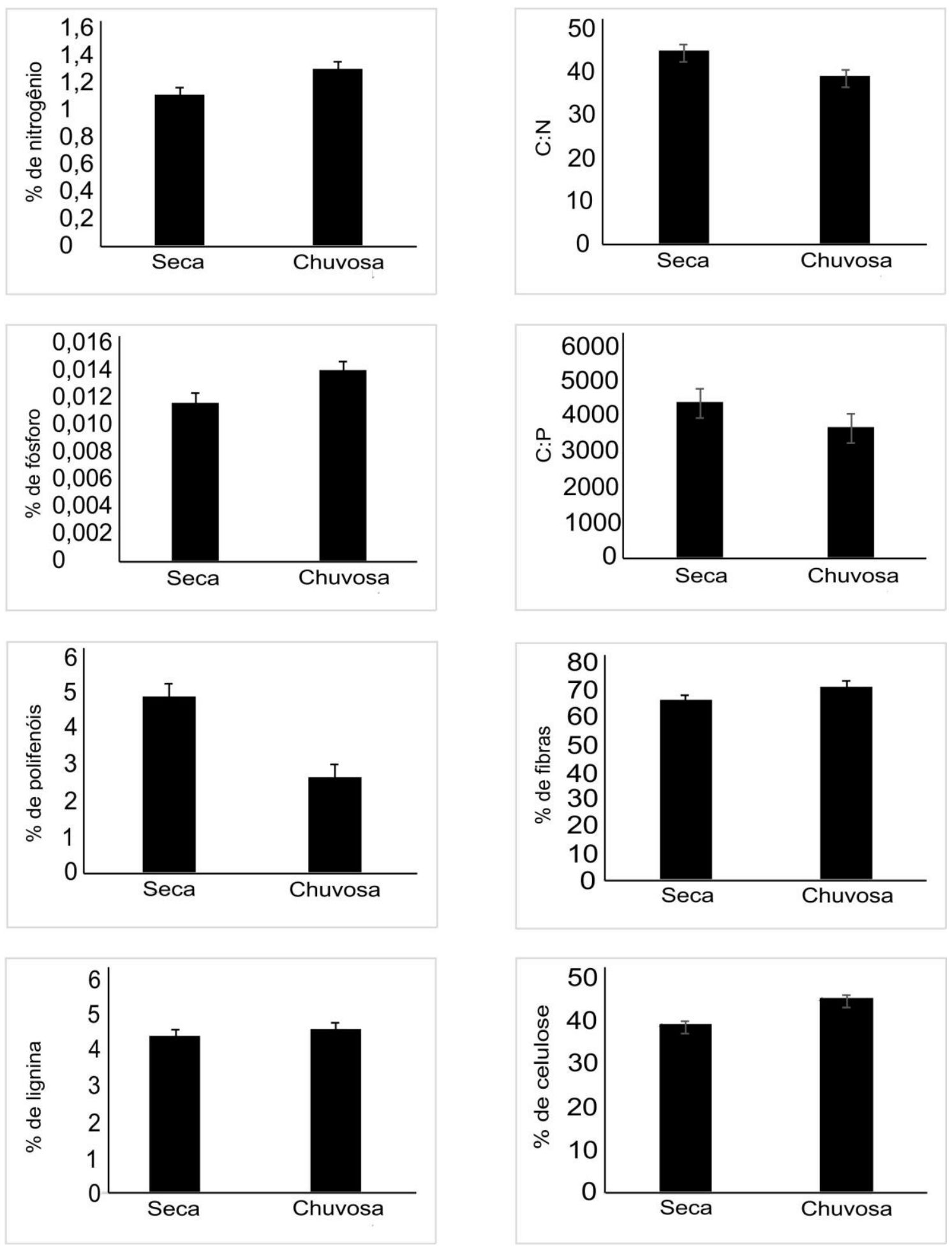

Figura 4 - Variação sazonal - entre as estações seca e chuvosa - dos compostos químicos no detrito foliar do aporte direto ao longo de 2 anos nos riachos estudados. 

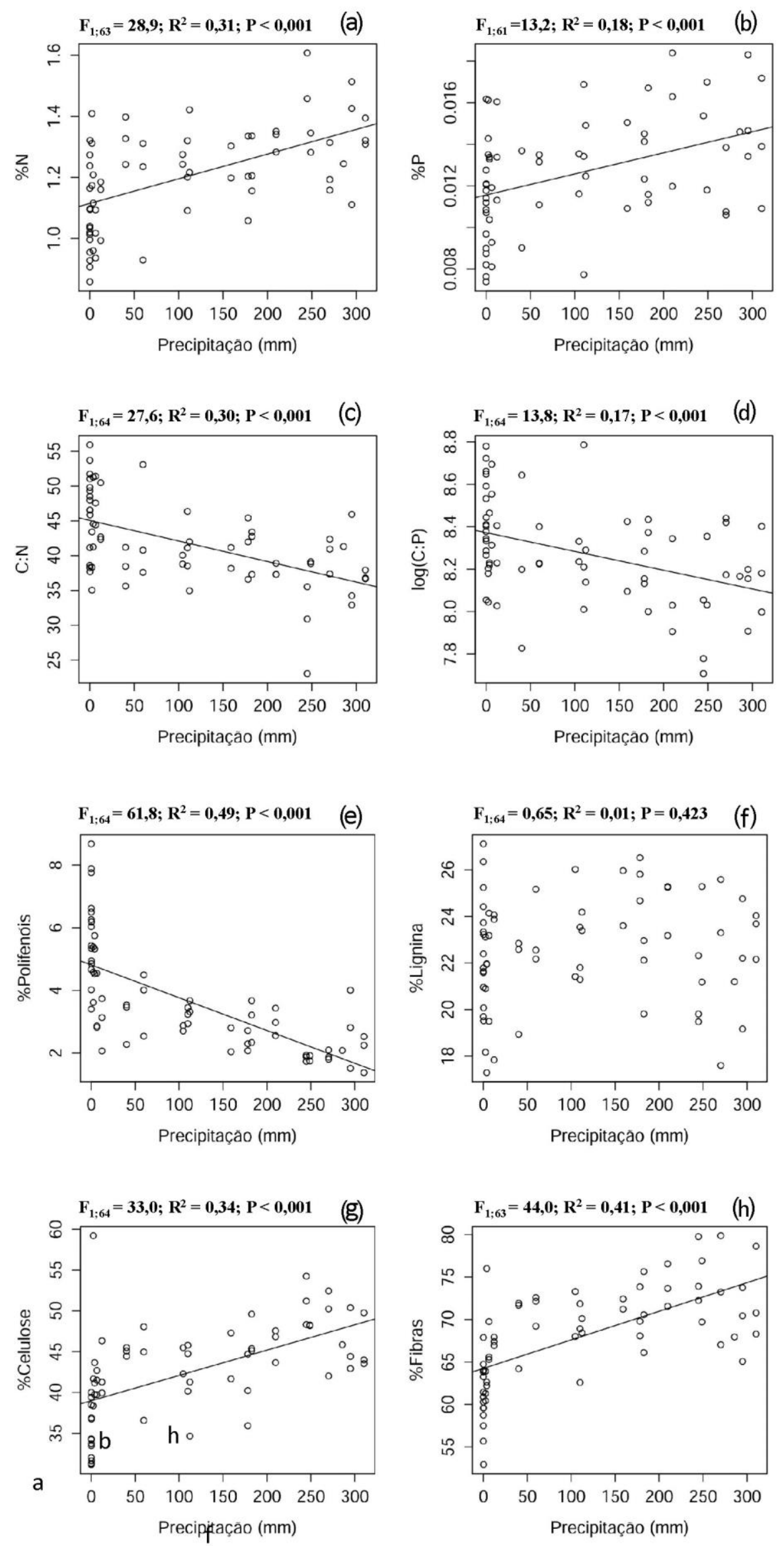
Figura 5 - Regressão linear explicando a relação entre os compostos químicos do detrito foliar com a precipitação: (a) N; (b) P; (c) estequiometria C:N; (d) estequiometria C:P; (e) compostos secundários (polifenóis); compostos estruturais (f) lignina; (g) celulose e (h) fibras.

\section{Discussão}

\section{Padrão sazonal da Química dos detritos foliares}

A pluviosidade é um dos fatores ambientais que mais influencia a sazonalidade do detrito foliar nas florestas tropicais (Zhang et al., 2014). Os resultados deste trabalho evidenciam que os padrões de sazonalidade na composição química do detrito foliar das florestas ripárias do Cerrado estão intimamente relacionados com o padrão climático deste bioma. Portanto, a pluviosidade afeta não só a produção de detrito (Sanches et al. 2008) como também a qualidade química do mesmo. Os maiores valores de $\mathrm{N}$ e $\mathrm{P}$ na estação chuvosa podem estar relacionados à maior absorção desses elementos dissolvidos na água do solo. Consequentemente, o detrito produzido na estação chuvosa tem melhor qualidade nutricional para os detritívoros do que o detrito liberado na estação seca. Desse modo, apesar da entrada de folhas ser maior na época seca, quando esperaríamos que haveria maior quantidade de nutrientes, a qualidade da folha é inferior à da época chuvosa (Parron et al., 2004). Além disso, em solos de baixa qualidade nutricional, a taxa de translocação de nutrientes é alta, resultando em detritos com baixa concentração nutricional (Cuevas \& Lugo, 1998; Sariyildiz \& Anderson, 2005). Os baixos níveis de fósforo no detrito (Tabela 1) podem ser consequência da eficiência na utilização e na translocação (Vitousek \& Sanford, 1986). Esses resultados corroboram a nossa hipótese 
de que durante a estiagem a quantidade de nutrientes no detrito foliar é menor e a razão $\mathrm{C}: \mathrm{N}$ e C:P é maior do que durante a estação chuvosa. Além da reabsorção de nutrientes antes da abscisão foliar, as plantas utilizam desse mecanismo para a produção de flores e frutos (Anu \& Sabu, 2007), assim a baixa quantidade de nutrientes durante a estação seca poderia estar relacionada ao período de floração das espécies ripárias do Cerrado. Lenza e Klink (2006), avaliaram que a floração das espécies lenhosas do Cerrado ocorre justamente no final do período seco, corroborando para a hipótese de que o baixo valor nutricional dos detritos nesse período ocorreu devido à retranslocação dos nutrientes da folha para as partes reprodutivas. Outra possibilidade para essa diferença química entre as estações é que, na estação chuvosa, o vento e a precipitação derrubam folhas verdes, as quais são mais concentradas em nutrientes do que folhas senescentes (Boeger et al., 2005). O mesmo padrão sazonal para a composição química da serapilheira foi encontrado em outros estudos realizados em florestas tropicais (Parron, 2004; Scalley et al. 2012; Jacobs et al. 2007; Townsend et al. 2007).

Dentre os nutrientes, o fósforo e o nitrogênio são fundamentais para o ciclo biogeoquímico dos ecossistemas porque a biota depende desses elementos para realizarem processos celulares vitais (Ensing \& Doyle, 2006). Além disso, a concentração desses nutrientes na folha reflete a disponibilidade dos mesmos no ecossistema (Townsend et al., 2007). Nos riachos, o P e o N são limitantes e afetam a produtividade primária e secundária (Schiller et al., 2008). Um aumento de nutrientes no riacho pode acelerar o processo de decomposição e de respiração gerando maior liberação de $\mathrm{CO}_{2} \mathrm{e}$ menor estoque de compostos recalcitrantes no riacho (Rosemond et al., 2015). Deste modo, para que a ciclagem biogeoquímica ocorra de maneira eficiente, é necessário que haja um equilíbrio de entrada dos detritos alóctones e, consequentemente, de nutrientes nos sistemas aquáticos. Neste trabalho, o funcionamento do ecossistema ripário do 
Cerrado tem um padrão sazonal em que os detritos que caem no riacho na época seca são menos palatáveis para os organismos aquáticos do que os detritos que caem na época chuvosa.

Nossos resultados demonstram que os compostos secundários foram encontrados em maiores concentrações na estação seca. Segundo a hipótese de balanço carbononutriente (CNBH- Bryant et al., 1983), quando a disponibilidade de nutrientes é baixa e limitante, as plantas alocam o carbono para a produção de compostos secundários (Kraus et al., 2003; Kraus et al., 2004a; Gonçalves-Alvim et al., 2011), o que diminui ainda mais o valor nutricional dos detritos durante esse período. Além do estresse nutricional, a radiação solar e o aumento de dióxido de carbono também favorecem a produção de polifenóis (Parsons et al., 2014). A produção de polifenóis pode ser uma estratégia para fixar carbono e nitrogênio quando há carbono em excesso e este não é utilizado para a fotossíntese (Booker \& Maier, 2001). No entanto, apesar da presença desses compostos diminuírem a qualidade do detrito para os organismos detritívoros, a presença dos polifenóis pode ter papel importante na dinâmica de ciclagem biogeoquímica do sistema ripário. Isso se deve à habilidade dos taninos de precipitar proteínas e atuar como uma fonte de carbono para que os micro-organismos imobilizem os compostos orgânicos de nitrogênio e diminuam a mineralização desse nutriente (Kraus et al., 2004b). Por outro lado, nos riachos, os compostos secundários são altamente lixiviados nos estágios iniciais de decomposição e não afetam a colonização microbiana no detrito (Abelho, 2001; Ardon \& Pringle, 2008). Muitas espécies nativas do Cerrado, como Protium spruceanum, Calophylum brasiliense e Vochysia pyramidalis tem elevadas perdas de polifenóis durante a lixiviação (Gomes, 2015; Salomão 2013). Portanto outros componentes químicos dessas espécies são mais importantes para o processo de decomposição do que os polifenóis. 
Enquanto a quantidade de polifenóis é menor durante a estação chuvosa, a concentração da celulose é maior. A lignina e a celulose são compostos estruturais da parede celular vegetal que evoluíram para conferir rigidez às plantas terrestres e, por isso, são características de cada espécie individual (Vanholme et al., 2010). No entanto, a biossíntese desses compostos pode ser induzida por condições de estresse derivadas de fatores bióticos ou abióticos (e.g: ferimentos, infecção patogênica, stress metabólico e perturbações na estrutura da parece celular vegetal; Austin \& Ballaré, 2010; Vanholme et al., 2010). Assim, pode-se supor que as plantas em questão, investem na produção de celulose na época chuvosa a fim de se proteger de micro-organismos patogênicos, como os fungos (Hättenschwiler \& Vitousek, 2000). Por outro lado, a maior quantidade de celulose na estação chuvosa pode ser derivada das espécies que liberam as folhas nessa época, as quais tem maiores concentrações desses compostos do que as espécies que liberam as folhas senescentes na estação seca. Assim, os constituintes químicos das folhas são influenciados não só pela precipitação, como também pela composição das espécies de plantas do pool de detritos (Cuevas \& Lugo, 1998). No entanto, a própria sazonalidade fenológica das espécies do Cerrado parece estar intimamente relacionada com a sazonalidade climática (Lenza \& Klink, 2006). A diversidade de espécies bem como a composição química - principalmente os compostos estruturais - de cada uma é um fator direcionador do processo de decomposição (Salomão, 2013; Coq, et al., 2010) e, consequentemente, de disponibilização de nutrientes no ecossistema.

Efeito da composição química do detrito foliar nos processos ecológicos

A queda de folhas de baixo valor nutricional - maior razão C:N e C:P - durante a estação seca pode refletir em baixas taxas de decomposição e acúmulo de material 
recalcitrante no riacho durante esse período e consequentemente, menor disponibilidade de nutrientes e menor produtividade. Rezende (2014) encontrou taxas de decomposição mais altas durante a estação chuvosa em veredas no Cerrado e associou este resultado à maior turbulência da água e à melhor qualidade do detrito. Congruente com esse resultado, Moretti et al. (2007) encontraram menores taxas de decomposição para mistura de espécies do Cerrado durante o período seco. Esses resultados são compatíveis com a sazonalidade da qualidade do detrito encontrada no presente estudo. A lentidão do processo de decomposição na seca pode resultar em menores taxas de emissão de $\mathrm{CO}_{2}$ pelo riacho durante esse período em relação à estação chuvosa. Ao entrar no riacho, o carbono terrestre é mineralizado pelos micro-organismos e invertebrados detritívoros, funcionando como estoque de carbono (Rosemond et al., 2015). Por isso, a manutenção da dinâmica nutricional dos ecossistemas ripários é fundamental inclusive para a contribuição dos riachos no ciclo global do carbono, no sentido de reter esse elemento no sistema e diminuir a emissão de $\mathrm{CO}_{2}$ (Hotchkiss et al., 2015).

A ciclagem de nutrientes em córregos é mantida, principalmente, pelo processo de decomposição dos detritos alóctones, da lixiviação da serapilheira e da percolação do lençol freático (Mitre, 2011). Durante a decomposição, a concentração de polifenóis em espécies arbóreas do Cerrado decai rapidamente enquanto a concentração de lignina e celulose permanece alta (Salomão, 2013). A abrasão física da água, durante os estágios iniciais de decomposição, retira os compostos secundários solúveis do detrito e os nutrientes, tornando-os disponíveis na água como matéria orgânica dissolvida (Gessner et al., 1999). Isso demonstra a importância da pluviosidade para o processo de lixiviação e a consequente entrada de nutrientes no ecossistema aquático. Após a lixiviação dos compostos secundários e dos nutrientes, os compostos estruturais (lignina e celulose) tornam-se direcionadores de uma decomposição lenta nesses ambientes (Ardón et al., 
2006). Isto se deve, por serem os compostos mais abundantes da massa foliar (Stursová et al., 2012) e por retardarem a colonização de micro-organismos e invertebrados, devido à sua conformação molecular complexa (Ardon \& Pringle, 2008). Além disso, a menor disponibilidade de nutrientes de solos de florestas tropicais favorece folhas ricas em compostos estruturais, uma vez que os nutrientes como $\mathrm{N}$ e $\mathrm{P}$ serão encontrados em baixas concentrações nos detritos (Coq et al. 2010). Visto que os compostos recalcitrantes são fatores -chave para a decomposição do detrito, a celulose é o composto cuja degradação é mais fácil do que a lignina, tem qualidade intermediária e serve como fonte de energia para os detritívoros (Loranger et al., 2002). Portanto, o aumento de celulose encontrado na época chuvosa pode não afetar negativamente a qualidade nutricional do detrito durante esse período.

Os compostos recalcitrantes são os responsáveis pela velocidade da transferência de energia na cadeia alimentar baseada em detrito ser muito mais lenta do que a assimilada pelos herbívoros, uma vez que os herbívoros consomem folhas verdes e os detritos são muito mais concentrados nesses compostos complexos de difícil degradação. Da mesma forma, pode-se inferir que a proporção da produção primária líquida da cadeia trófica aquática detritívora, baseada em recurso alóctone, é muito maior quando comparada com a cadeia trófica herbívora, uma vez que as plantas terrestres alocam muito da sua energia para a produção desses compostos difíceis de serem degradados (Ricklefs, 2010). Diante desses fatos, sugerimos que na época seca a produtividade é maior devido à alta quantidade de compostos recalcitrantes, os quais tem muito mais energia do que nutrientes e carboidratos simples, mesmo que a taxa de decomposição nesse período seja mais lenta.

Alguns trabalhos encontraram maior concentração fúngica no detrito durante o período chuvoso (Mitre, 2011; Sales et al., 2014), coincidindo com nossos dados de maior 
concentração de celulose. Sendo assim, durante a época chuvosa a planta investe na biossíntese de celulose, uma vez que os fungos se proliferam nesta época e colonizam os detritos foliares. Ao colonizarem os detritos, os fungos aceleram o processo de decomposição, degradam os compostos recalcitrantes e tornam os detritos mais palatáveis para invertebrados detritívoros. Tudo isso reforça a ideia de que o alto índice de celulose na estação chuvosa ocorre devido à uma adaptação fisiológica da planta para evitar ataques de micro-organismos patogênicos (Miedes et al. 2014).

Os fungos e bactérias são considerados organismos importantes no processo de decomposição em ambientes tropicais porque a quantidade de invertebrados fragmentadores é muito reduzida (Gonçalves et al., 2006; Gonçalves et al., 2012). Os hifomicetos aquáticos (principais fungos decompositores dos detritos foliares; Graça et al., 2015) parecem seguir o mesmo padrão que a dinâmica de nutrientes do presente estudo, com baixa densidade no período de estiagem e picos no início da estação chuvosa (Sales et al., 2014). Enquanto os invertebrados tem seus picos no final da estação chuvosa, entre março e maio (Bezerra, 2012). A sequência sazonal entre os nutrientes encontrados nesse estudo corrobora as sequências de fungos e invertebrados encontrados nos estudos acima mencionados durante a decomposição. Essa sequência é congruente com a sequência de decomposição do folhiço: nos estágios iniciais a lixiviação retira compostos solúveis em água, como os polifenóis, em seguida fungos e bactérias colonizam o detrito, produzem enzimas capazes de degradar compostos recalcitrantes e tornam o detrito palatável para que invertebrados detritívoros fragmentem o folhiço em partículas menores (Gessner et al., 1999; Graça, 2001). Assim, essa sucessão de acontecimentos temporais demonstra um padrão evidente do funcionamento do ecossistema ripário do Cerrado.

Estudos de dinâmica de matéria orgânica em riachos tropicais tem mostrado que existem poucas espécies que contribuem bastante para o pool de matéria orgânica que 
entra no riacho (Gonçalves et al., 2006; Gonçalves et al., 2014). De fato, apenas $14 \%$ das espécies identificadas tiveram grande contribuição em biomassa ao longo do período investigado. Isto indica que a queda de folhas não é homogênea, em que cada espécie vegetal tem uma contribuição relativa em períodos específicos ao longo do ano. Apesar da especificidade nutricional de cada espécie num ambiente diverso ser significativa (Mitre, 2011), neste trabalho ficou evidente que a composição química da mistura de espécies tem um padrão sazonal, o qual está relacionado ao padrão climático do bioma e não a composição de espécies. Este padrão influencia os processos ecossistêmicos como a decomposição, a ciclagem biogeoquímica e a produtividade - sendo esta maior na estação seca do que na estação chuvosa, uma vez que os compostos recalcitrantes demandam mais energia para serem produzidos.

Alguns trabalhos com espécies do Cerrado, como Emmotuns nitens, Maprounea guianensis, Callophylum brasiliense, Myrcia guianensis e Protium sp., demonstraram que essas espécies tem taxas de decomposição lenta principalmente devido à alta concentração de compostos recalcitrantes e à alta razão C:N (Moretti et al. 2007; Mitre, 2011; Salomão 2013). Todas essas espécies foram encontradas no presente estudo em proporções significativas ao longo de um ano e convergem com nossos resultados em que a mistura dos detritos contém baixa quantidade de nutrientes e alta concentração de compostos recalcitrantes, principalmente lignina e celulose. Desta forma, a composição química das espécies que compõem a vegetação ripária pode ser mais importante para o processo de decomposição do que outros fatores abióticos como a temperatura.

A composição química da mistura das espécies vegetais é diferente da composição química de cada espécie individualmente (Chapman et al., 1988). A mistura de espécies pode ou não ter efeitos sobre a comunidade detritívora. Algumas espécies podem ter efeito aditivo sobre outras, ou seja, possuir substâncias inibidoras (e.g.: polifenóis, 
lignina) que diminuam a taxa de decomposição nas demais (Swan \& Palmer, 2004). Embora, alguns trabalhos não tenham encontrado relação entre a mistura de espécies e a taxa de decomposição (Schindler \& Gessner, 2009), o presente trabalho mostrou que existe um padrão de qualidade nutricional bastante significativo ao longo do ano. Leroy \& Marks (2006) mostraram que a assembleia de invertebrados que coloniza a mistura de detritos difere da que coloniza cada espécie individualmente. Da mesma forma Swan \& Palmer (2006) verificaram que a abundância e a biomassa dos detritívoros varia entre a mistura de detritos e os detritos de cada espécie separadamente. No presente estudo, por exemplo, foram encontradas 140 espécies, um número elevado de espécies dentro do bioma (França et al., 2009), inclusive quando comparado com outras florestas tropicais (Lisboa et al., 2015; Gonçalves et al., 2014). Portanto, estudos que queiram responder perguntas relativas aos processos ecológicos em zonas ripárias tropicais devem levar em consideração não só espécies-chave individualmente, mas sim a mistura de espécies, já que essas zonas são consideradas de elevada diversidade biológica (Hoorens et al., 2003).

\section{Considerações Finais}

O presente estudo demonstrou que existe uma dinâmica nutricional dos detritos foliares alóctones que abastecem os cursos d'água e que essa dinâmica está fortemente relacionada ao clima estacional do Cerrado com a precipitação sendo um fator determinante da concentração dos compostos químicos dos detritos foliares das espécies ripárias do Cerrado. A composição química dos detritos que caem no período de estiagem tem pior qualidade nutricional para os micro e macro-organismos do que os que caem durante a época chuvosa, o que corrobora com a hipótese deste estudo. Essa dinâmica química temporal é fundamental para a manutenção dos processos ecológicos (e.g. 
decomposição, ciclagem biogeoquímica, cadeia trófica) aquáticos em zonas ripárias e para a estrutura da comunidade biológica. O padrão sazonal dos nutrientes pode refletir num padrão sazonal dos processos ecológicos, em que a decomposição, por exemplo, ocorre de maneira mais lenta na época seca do que na época chuvosa. Isso poderia refletir em uma maior produtividade na seca do que na estação chuvosa devido à alta concentração dos compostos recalcitrantes (demandam mais energia para serem produzidos), nesse período.

A composição florística também variou temporalmente e indicou que as espécies ali presentes tem contribuições relativas diferentes ao longo do ano. Deste modo, qualquer mudança na composição florística das zonas ripárias pode alterar a dinâmica nutricional, qualidade do detrito, e, consequentemente, a produtividade e os processos ecológicos que mantém a qualidade da água. Os padrões sazonais climáticos, fenológicos e nutricionais revelam como os fatores bióticos e abióticos estão intimamente conectados num equilíbrio dinâmico chamado ecossistema, como proposto por Arthur Tansley (1935).

Conclui-se que as zonas ripárias do Cerrado exercem importante efeito nutricional para os riachos de cabeceira. Resta avaliar e monitorar se as plantas manterão esse padrão químico com as alterações climáticas atuais e com as mudanças de uso do solo próximo à essas zonas e, quais seriam os efeitos dessas mudanças no ecossistema aquático.

\section{Referências}

Abelho, M. (2001) From litterfall to breakdown in streams: a review. The Scientific World, 1, 656- 680.

Acuña, V., Giorgi, A., Muñoz, I., Sabater, F. \& Sabater, S. (2007) Meteorological and riparian influences on organic matter dynamics in a forested Mediterranean stream. Journal of the North American Benthological Society, 26, 54-69, 
Anu, A. \& Sabu, T. K. (2007) Seasonal variation in the litter chemical quality of a wet evergreen forest in the Western Ghats. Current Science, 93, 391-394,

Ardón, M., Stallcup, L. A. \& Pringle, C. M. (2006) Does leaf quality mediate the stimulation of leaf breakdown by phosphorus in Neotropical streams? Freshwater biology, 51, $618-633$.

Ardón, M. \& Pringle, C. M. (2008) Do secondary compounds inhibit microbial - and insect - mediated leaf breakdown in a tropical rainforest stream, Costa Rica? Oecologia, 155, 311-323.

Austin, A. T. \& Ballaré, C. L. (2010) Dual role of lignin in plant litter decomposition in terrestrial ecosystems. Proceedings of the National Academy of Sciences of the United States of America, 107, 4618-4622.

Barlocher, F. \& Graça, M.A.S. (2005) Total phenolics. In: Graça, M. A. S.; Barlocher, F.; Gessner, M. O. (eds), Methods to Study Litter Decomposition: A Practical Guide, 115120. Springer. The Netherlands.

Berkowitz, J. F., Summers, E. A., Noble, C. V., White, J. R. \& DeLaune, R. D. (2014) Investigation of biogeochemical function proxies in headwater streams across a range of channel and catchment alterations. Environmental Management, 53, 534 - 548.

Bezerra, F. A. (2012) Variação temporal da decomposição de detritos foliares em córregos de cabeceira no Cerrado. Dissertação, Universidade de Brasília.

Booker, F. L. \& Maier, C. A. (2001) Atmospheric carbon dioxide, irrigation and fertilization effects on phenolic and nitrogen concentration in loblolly pine (Pinus taeda) needles. Tree Physiology, 21, 609-616.

Boeger, M.R.T., Wisniewski, C. \& Reissmann, C.B. (2005) Nutrientes foliares de espécies arbóreas de três estádios sucessionais de floresta ombrófila densa no sul do Brasil. Acta Botanica Brasilica 19, 167-181.

Boyero, L., Ramírez, A., Dudgeon, D. \& Pearson, R. G. (2009) Are tropical streams really different? Journal of The North American Benthological Society, 28, 397- 403.

Bryant, J.P., Chapin, F.S. \& Klein, D.R. (1983) Carbon/ nutrient balance of boreal plants in relation to vertebrate herbivory. Oikos, 40, 357-36. 
Chapman, K., Whittaker, J. B. \& Heal, O. W. (1988) Metabolic and faunal activity in litters of tree mixtures compared with pure stands. Agriculture, Ecosystems and Environment, 24, 33-40.

Coq, S., Souquet, J. M., Meudec, E., Cheynier, V. \& Hattenschwiler S. (2010) Interspecific variation in leaf litter tannins drives decomposition in a tropical rain forest of French Guiana. Ecology, 91, 2080- 2091.

Crawley, M. J. (2007) The R Book. John Wiley \& Sons Ltd, England.

Cuevas, E. \& Lugo, A. E. (1998) Dynamics of organic matter and nutriente return from litterfall in stands of ten tropical tree plantation. Forest Ecology and Management, 112 263-279.

Dosskey, M. G., Vidon, P., Gurwick, N. P., Allan, C. J., Duval, T. P. \& Lowrance, R. (2010) The role of riparian vegetation in protecting and improving chemical water quality in streams. Journal of the American water Resources Association, 46, 261-277.

Ensign, S.H. \& Doyle, M.W. (2006) Nutrient spiraling in streams and river network. Journal of Geophysical Research, 111, 1- 13.

Felfili, M. C. \& Felfili, J. M. (2001) Diversidade alfa e beta no Cerrado sensu stricto da chapada Pratinha, Brasil. Acta Botanica Brasilica, 15,243-254.

Franca, J. S., Gregorio, R. S., De Paula, J. D., Gonçalves, J. F. Jr., Ferreira, F. A. \& Callisto, M. (2009) Composition and dynamics of allochthonous organic matter inputs and benthic stock in a Brasilian stream. Marine and Freshwater Research 60, 990-998.

Gessner, M.O., Chauvet, E. \& Dobson, M. (1999) A perspective on leaf litter breakdown in streams. Oikos, 85, 377-384.

Gessner, M. O. (2005) Proximate Lignin and Cellulose. In: Graça, M. A. S.; Barlocher, F.; Gessner, M. O. (eds), Methods to Study Litter Decomposition: A Practical Guide, 115120. Springer. The Netherlands.

Gomes, P. P. (2015) Influência da química do detrito foliar e da água sobre a comunidade de hifomicetos aquáticos, Tese, Universidade de Brasília. 
Gonçalves, J. F. Jr., Rezende, R. S., Gregório, R. S. \& Valentin, G. C. (2014) Relationship between dynamics of litterfall and riparian plant species in a tropical stream. Limnologica, 44, 40-48.

Gonçalves, J. F. Jr. \& Callisto, M. (2013) Organic -matter dynamics in the riparian zone of a tropical headwater stream in Southern Brazil. Aquatic Botany, 109, 8- 13.

Gonçalves, J. F. Jr., Rezende, R. S., Martins, N.M. \& Gregório, R. S. (2012) Leaf breakdown in na Atlantic Rain Forest stream. Austral Ecology, 37, 807-815.

Gonçalves, J. F. Jr., França, J.S. \& Callisto, M. (2006) Dynamics of allocthonous organic matter in a tropical Brazilian headstream. Brazilian Archives of Biology and Technology, 49, 967- 973.

Gonçalves-Alvim, S. J., Lana, T. C., Ranieri, B. D. \& Fernandes, G. W. (2011) Test of hypotheses about herbivory and chemical defences of Qualea parviflora (Vochysiaceae) in Brazilian Cerrado. Revista Brasileira de Botânica, 34, 2230-230.

Gonzáles, E. (2012) Seasonal patterns of litterfall in the floodplain forest of a large Mediterranean river. Limnetica, 31, 173-186.

Graça, M. A. S. (2001) The role of invertebrates on leaf litter decomposition in streams a review. International Review of Hydrobiology, 86, 383-393.

Graça, M. A. S., Hyde, K. \& Chauvet, E. (2015) Aquatic hyphomycetes and litter decomposition in tropical - subtropical low order streams. Fungal Ecology, 2015.

Gregory, S.V., Swanson, F.J., Mckee, W. A. \& Cummins, K. W. (1991) An ecosystem perspective of riparian zones. BioScience, 41, $540-551$.

Guendehou, G. H. S., Liski, J., Tuomi, M., Moudachirou, M., Sinsin, B. \& Makipaa, R. (2014) Decomposition and changes in chemical composition of leaf litter of five dominant tree species in a west African tropical forest. Tropical Ecology, 55, 207-220.

Hättenschwiler, S. \& Vitousek, P. M. (2000) The role of polyphenols in terrestrial ecosystem nutrient cycle. Trends in Ecology \& Evolution, 15, 238-243.

Hoorens, B., Aertes, R. \& Stroetenga, M. (2002) Litter quality and interactive effects in litter mixtures: more negative interactions under elevated CO2? Journal of Ecology, 90, 1009-1016. 
Hoorens, B., Aertes, R. \& Stroetenga, M. (2003) Does initial litter chemistry explain mixture effects on decomposition? Oecologia, 137, 578- 586.

Hotchkiss, E. R., Hall Jr, R. O., Sponseller, R. A., Butman, D., Klaminder, J., Laudon, H., Rosvall, M. \& Karlsson, J. (2015) Sources of and processes controlling $\mathrm{CO}_{2}$ emissions change with the size of streams and rivers. Nature Geoscience, 8, 696- 699.

Jacobs, S. M., Bechtold, J.S., Biggs, H.C., Grimm, N. B., Lorentz,S., McClain, M.E., Naiman, R.J., Perakis, S.S., Pinay, G. \& Scholes, M. C. (2007) Nutrient Vectors and Riparian Processing: a review with special reference to African Semiarid Savanna Ecosystems. Ecosystems, 10,1231-1249.

Kozovits, A. R., Bustamante, M. M. C., Garofalo, C. R., Bucci, A., Franco, A., Goldstein, G. \& Meinzer, F. C. (2007) Nutrients resorptions and patterns of litter production and decompositions in a Neotropical Savanna. Functional Ecology, 21, 1034-1043.

Kraus, T. E. C., Dahlgren, R. A. \& Zasoski, R. J. (2003) Tannins in nutrient dynamics of forest ecosystems - a review. Plant and Soils, 256, 41-66.

Kraus, T. E. C., Zasoski, R. J. \& Dahlgren, R. A. (2004a) Fertility and pH effects on condensed tannin concentrations on foliage and roots. Plant and Soils, 262, 95-109.

Kraus, T. E. C., Zasoski, R. J., Dahlgren, R. A., Horwath, W. R. \& Preston, C.M. (2004b) Carbon and nitrogen dynamics in a forest soil amended with purified tannins from different plant species. Soil, Biology and Biogeochemistry, 36, 309-321..

Larrañaga, S., Díez, J. R., Elosegi, A. \& Pozo, J. (2003) Leaf retention in streams of Aguera Basin (northern Spain). Aquatic Sciences, 65, 158-166.

Lecerf, A., Risnoveanu, G., Popescu, C., Gessner, M. O. \& Chauvet, E. (2007) Decomposition of diverse litter mixtures in streams. Ecology, 88, 219- 227.

Lenza, E. \& Klink, C.A. (2006) Comportamento fenológico de espécies lenhosas de um cerrado sentido restrito de Brasília, DF. Revista Brasileira de Botânica, 29, 627- 638.

Leroy, C. J. \& Mark, J. C. (2006) Litter quality, stream characteristics and litter diversity influence decomposition rates and macroinvertebrates. Freshwater Biology, 51, 605-617. 
Lima, J.E.F.W. \& Silva, E.M. (2008) Recursos Hídricos do Bioma Cerrado - Importância e situação. In: Sano, S. M., Almeida, S. P. \& Ribeiro, J. F. Cerrado: Ecologia e Flora, Embrapa Cerrados - Brasília,DF, 2, 279.

Lisboa, L. K., Silva, A. L. L., Siegloch, A. E., Gonçalves Jr, J. F \& Petrucio, M. M. (2015) Temporal dynamics of allochthonous coarse particulate organic matter in a subtropical Atlantic rainforest Brazilian stream. Marine and Freshwater research, 1-7.

Loranger, G., Ponge, J.F., Imbert, D. \& Lavelle, P. (2002) Leaf decomposition in two semi-evergreen tropical forest. Biology and Fertility of Soils, 35, 247- 252.

Lovett, G.M., Weathers, K. C. \& Arthur, M.A. (2002) Control of nitrogen loss from forested watershed by soil carbon:nitrogen ratio and tree species composition. Ecosystems, 5, 712-718.

Meier, C. L. \& Bowman, W. D. (2008) Phenolic rich-leaf carbon fractions differentially influence microbial respiration and plant growth. Oecologia, 158, 95 -107.

Miedes, E., Vaholme, R., Boerjan, W. \& Molina, A. (2014) The role of secondary cell wall in plant resistance to pathogens. Frontiers in Plant Science, 5, 78-90.

Mitre, S. K. (2011) Decomposição de detritus foliares alóctones e dinâmica de nutrientes em sistema lótico no Cerrado. Dissertação, Universidade de Brasília.

Moretti, M., Gonçalves, J.F. Jr \& Callisto, M. (2007) Leaf breakdown in two tropical streams: differences between single and mixed species packs. Limnologica, 37, 250-258.

Naiman, R. J., Bilby, R. E. \& Bisson, P. (2000)A. Riparian ecology and management in the Pacific Coastal Rain Forest. BioScience, 50, 996-1011.

Naiman, R.J., Décamps, H. \& McClain, M.E. (2005) Riparian Ecology, Conservation and Management of Streamside Communities. BioScience, 50, 996-1011.

Parron, L.M. (2004) Aspectos da ciclagem de nutrientes em função do gradiente topográfico em uma Mata de Galeria no Distrito Federal, Tese, Universidade de Brasília.

Parron, L. M., Bustamante M. M. C. \& Markewitz, D. (2011) Fluxes of nitrogen and phosphorus in a gallery forest in the Cerrado of central Brazil. Biogeochemistry, 105, 89104. 
Parsons, S. A., Valdez-Ramirez, V., Congdon, R. A. \& Williams, S. E. (2014) Contrasting patterns of litterfall seasonality and seasonal changes in litter decomposability in a tropical rainforest region. Biogeosciences, 11, 5047-5056.

Pettit, N. E., Davies, T., Fellman, J. B., Grierson, P. F., Warfe, D. M. \& Davies, P. M. (2012) Leaf litter chemistry decomposition and assimilation by macroinvertebrates in two tropical streams. Hydrobiologia, 680, 63- 77.

Rezende, R. S. (2014) Decomposição de detritos foliares em sistemas ripários tropicais: efeitos das escalas espacial e temporal. Tese, Universidade de Brasília.

Ribeiro, J. F. \& Walter, B. M. T. (2001) As Matas de Galeria no contexto do bioma Cerrado. In: Ribeiro, J. F., Fonseca, C. E. L. \& Sousa-Silva, J. C. Cerrado: caracterização e recuperação de Matas de Galeria. Planaltina: Embrapa Cerrados, 899 p.

Ribeiro, J. F. \& Walter, B. M. T. (2008) As principais fitofisionomias do bioma Cerrado. In: Sano, S. M., Almeida, S. P. \& Ribeiro, J. F. Embrapa Cerrados, Brasília - DF: Embrapa Informação Tecnológica, 1, 153 - 212.

Ricklefs, R.E. (2010) A Economia da Natureza. $6^{\text {a }}$ ed. Editora Guanabara Koogan, Rio de Janeiro.

Rosemond, A. D., Benstead, J. P., Bumpers, P. M., Gulis, V., Kominoski, J. S., Manning, D. W. P., Suberkropp, K. \& Wallace, J. B. (2015) Experimental nutrient additions accelerate terrestrial carbon loss from stream ecosystems. Science, 347, 1142 -1144.

Sales, M. A., Gonçalves, J. F. Jr., Dahora, J. S. \& Medeiros, A. O. (2014) Influence of leaf quality in microbial decomposition in a headwater stream in the Brazilian Cerrado: a 1-year study. Microbial Ecology.

Salomão, V. P. (2013) Efeitos antrópicos do represamento de um riacho no Cerrado na decomposição foliar. Dissertação, Universidade de Brasília.

Sanches, L., Valentini, C.M.A., Júnior, O.B.P., Nogueira, J. S., Vourlitis, G. L., Biudes, M. S., Silva, C. J., Bambi, P. \& Lobo, F. A. (2008) Seasonal and interanual litter dynamics of a tropical semideciduous forest of the southern Amazon Basin, Brazil. Journal of Geophysical Research, 113, 1-9. 
Sariyildiz, T. \& Anderson, J. M. (2005) Variation in the chemical composition of green leaves and leaf litters from three deciduous tree species growing on different soil types. Forest Ecology and Management, 210,303 - 319.

Scalley, T. H., Scatena, F.N., Moya, S.; \& Lugo, A. E. (2012) Long-term dynamics of organic matter and elements exported as coarse particulates from two Caribbean montane watersheds, Journal of Tropical Ecology, 28, 127-139.

Schiller, D., Martí, E., Riera, J. L., Ribot, M., Argerich, A., Fonollà, P. \& Sabater, F. (2008) Inter-annual, annual and seasonal variation of $\mathrm{P}$ and $\mathrm{N}$ retention in an perennial and in an intermittent stream. Ecosystems, 11, 670-687.

Seifert, L. I. \& Scheu, S. (2012) Linking aquatic and terrestrial food webs - Odonata in boreal ecosystems. Freshwater Biology, 57, 1449- 1457.

Speaker, R., Moore, K. \& Gregory, S. (1984) Analysis of the process of retention of organic matter in stream ecosystems. Verhandlungen des Internationalen Verein Limnologie, 22, 1835-1841.

Stursová, M., Zifcáková, L., Leigh, M. B., Burgess, R. \& Baldrian, P. (2012) Cellulose utilization in forest litter and soil: identification of bacterial and fungal decomposers FEMS Microbiology Ecology, 80, 735-746.

Swan, C. M. \& Palmer, M. A. (2004) Leaf diversity alters litter breakdown in a Piedmont stream. Journal of the North American Benthological Society, 23, 15-28.

Swan, C. M. \& Palmer, M. A. (2006) Composition of speciose leaf litter alters streams detritivore growth, feeding activity and leaf breakdown. Oecologia, 147, 469-478.

Teresa, F. B. \& Casatti, L. (2010) Importância da vegetação ripária em região intensamente desmatada no sudeste do Brasil: um estudo com peixes de riacho. PanAmerican Journal of Aquatic Science, 5, 444 - 453.

Townsend, A. R., Clevelend, C. C., Asner, G. P. \& Bustamante, M. M. C. (2007) Controls over foliar N:P ratios in tropical rains forests. Ecology, 88, 107-118.

Wantzen, K. M. \& Wagner, R. (2006) Detritus processing by invertebrate shredders: a neotropical-temperate comparison. Journal of the North American Benthological Society, 25, 216-232. 
Wantzen, K.M, Yule, C.M., Mathooko, J.M. \& Pringle, C.M. (2008) Organic Matter Processing in Tropical Streams. In: Dudgeon, D. \& Cressa, C. (Org). Tropical Stream Ecology. Elsevier, USA, p. 44-64.

Vanholme, R., Demedts, B., Morreel, K., Ralph, J. \& Boerjan, W. (2010) Lignin Biosythesis and Structure. Plant Physiology, 153, 895-905.

Vannote, R. L., Minshall, G. W., Cummins, K. W., Sedell, J. R. \& Cushing, C. E. (1980) The River Continuum Concept. Canadian Journal of Fisheries and Aquatic Science, 37, $130-137$.

Vitousek, P. M. \& Sanford, R. L. (1986) Nutrient cycling in moist tropical forest, Annual Review of Ecology and Systematics, 17, 137- 167.

Zhang, H., Yuan, W., Dong, W., Liu, S. (2014) Seasonal patterns of litterfall in forest ecosystem worldwide. Ecological Complexity, 20, 240-247. 